\title{
Functional Assessment of the Esophagogastric Junction After Laparoscopic Sleeve Gastrectomy
}

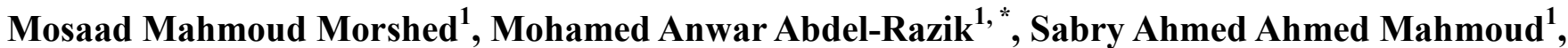 \\ Alaa Magdy Abou El-Fotouh ${ }^{1}$, Sameh Hany Emile ${ }^{1}$, Hosam Ghazy Elbanna ${ }^{1}$, Mohamed Youssef ${ }^{1}$, \\ Emad Abdallah ${ }^{1}$, Nabil Ali Gad El-Hak ${ }^{2}$
}

${ }^{1}$ General Surgery Department, Mansoura Faculty of Medicine, Mansoura city, Egypt

${ }^{2}$ Gastroenterology Surgical Center, Mansoura Faculty of Medicine, Mansoura City, Egypt

\section{Email address:}

Morshedmm@hotmail.com (M. M. Morshed), M_anwer81@yahoo.com (M. A. Abdel-Razik), Sabrybadr@yahoo.com (S. A. A. Mahmoud), Alaamagdy72@yahoo.com (A. M. A. El-Fotouh), Sameh200@hotmail.com (S. H. Emile), Hosamelbanna@hotmail.com (H. G. Elbanna), M_elkhir@yahoo.com (M. Youssef),Emad1976@gmail.com (E. Abdallah), Gadelhak_n_eg@hotmail.com (N. A. G. El-Hak)

${ }^{*}$ Corresponding author

\section{To cite this article:}

Mosaad Mahmoud Morshed, Mohamed Anwar Abdel-Razik, Sabry Ahmed Ahmed Mahmoud, Alaa Magdy Abou El-Fotouh, Sameh Hany Emile, Hosam Ghazy Elbanna, Mohamed Youssef, Emad Abdallah, Nabil Ali Gad El-Hak. Functional Assessment of the Esophagogastric Junction After Laparoscopic Sleeve Gastrectomy. Journal of Surgery. Vol. 4, No. 5, 2016, pp. 105-113. doi: 10.11648/j.js.20160405.14

Received: August 22, 2016; Accepted: August 30, 2016; Published: September 13, 2016

\begin{abstract}
The relation between bariatric procedures and gastroesophageal reflux disease (GERD) seems to be quite complex and unclear. The present trial aimed to assess the functional changes that occur in the esophagogastric junction (EGJ) after laparoscopic sleeve gastrectomy (LSG) using objective methods for assessment as esophageal manometry and ambulatory 24hour $\mathrm{pH}$ monitoring in attempt to correlate these changes with either the deterioration or the alleviation of GERD symptoms after LSG. This prospective case series study was conducted on patients with morbid obesity who were treated with LSG in the General Surgery Department, Mansoura University Hospitals. All patients were assessed pre- and postoperatively for the presence of GERD both clinically and with esophagogastrodudenoscopy (EGD). Functional assessment of the EGJ was done before LSG and at six months of follow-up using esophageal manometry and ambulatory 24-hour esophageal pH monitoring. Twenty morbidly obese patients ( 16 females \& 4 males) of a mean age of 29.4 years had underwent functional assessement of the EGJ before and at six months after LSG. The mean BMI at the time of surgery was $51.6 \pm 8.7 \mathrm{~kg} / \mathrm{m}^{2}$. Thirteen patients had no symptoms related to GERD preoperatively, all of these patients remained symptom-free after LSG. Seven (35\%) patients had preoperative symptoms of GERD, three reported no change in their symptoms at six months of follow-up, and four reported significant improvement of their symptoms six months after LSG. Overall, no significant changes in the manometric parameters were noticed. However, a significant decrease in the resting LES pressure was noticed after LSG in patients with no preoperative GERD symptoms, but not in patients with symptomatic GERD. Seven (35\%) patients had high preoperative DeMeester scores and prolonged total acid reflux time percentage, all of them got normalized postoperatively except two patients. Absolute concordance of the four parameters studied was observed in seven (35\%) patients only. Esophageal manometry has a limited utility in the detection or exclusion of GERD postoperatively since the significant decrease in the resting LES pressure observed was not associated with symptoms of GERD. On the other hand, 24-hour pH monitoring was able to detect improvement or persistence of GERD in the patients studied.
\end{abstract}

Keywords: Sleeve Gastrectomy, Functional Assessment, Esophagogastric Junction, Esophageal Manometry, pH-Metry, Morbid Obesity

\section{Introduction}

Morbid obesity is known to be associated with esophageal motility disorders, and has been documented to be an independent risk factor for gastroesophageal reflux disease (GERD) as obesity increases its incidence by around 50\% [1]. 
There is a number of mechanisms for the development of GERD in the morbidly obese patients including transient lower esophageal sphincter (LES) relaxations [2], hypotensive LES [3], and anatomic disruption of the esophagogastric junction (EGJ) as in hiatal hernia [4].

The mechanical dysfunction of the LES was proposed by Ayazi et al. [5] to be the most important contributing factor to the development of GERD. Wu and colleagues [6] also reported an association between obesity and frequent transient LES relaxations. However, it is important to note that incompetent LES can be found in asymptomatic patients without clinical evidence of GERD [7].

It seems that the pathogenesis of GERD is attributed to the collaboration of the aforementioned three factors rather than a single factor on its own; nonetheless the interplay between these factors has not been well elucidated. It has been proposed that transient LES relaxations are responsible for mild symptoms whereas the more severe symptoms are caused by the other two factors [8].

Unlike the clear relation between GERD and obesity; the relation between bariatric procedures and GERD seems to be far more complex and unclear. While certain procedures are associated with improvement of GERD symptoms in patients with morbid obesity; other procedures can either alleviate or increase the clinical symptoms of GERD [9].

In most of the previous studies evaluating the effect of bariatric surgery on GERD, the diagnosis of GERD was mainly made on clinical basis following the practice guidelines that considered the typical symptoms of GERD as the mainstay for the diagnosis [10]. Only a few studies applied a variety of diagnostic modalities that can help in establishing an objective diagnosis of GERD. These modalities include esophagogastrodudenoscopy (EGD), ambulatory 24-hour esophageal $\mathrm{pH}$ monitoring, and esophageal manometry [11].

The present trial aimed to assess the functional changes that occur in the EGJ after laparoscopic sleeve gastrectomy (LSG) using objective methods for assessment as esophageal manometry and ambulatory 24-hour $\mathrm{pH}$ monitoring in attempt to correlate these changes with either the deterioration or the alleviation of GERD symptoms after LSG.

\section{Patients and Methods}

\subsection{Study Design and Setting}

This prospective case series study was conducted in the period between March 2012 and September 2013 on twenty patients with morbid obesity who were treated with LSG in the General Surgery Department, Mansoura University Hospitals. Ethical approval of the study protocol was obtained from board of general surgery department of Mansoura Faculty of Medicine.

\subsection{Eligibility Criteria}

Patients with morbid obesity of both genders, aging between 18 and 60 years were included. Patients had a body mass index $(\mathrm{BMI})>40 \mathrm{~kg} / \mathrm{m}^{2}$ or BMI $>35 \mathrm{~kg} / \mathrm{m}^{2}$ with at least one assocaited comorbidity. Patients had to be cooperative and motivated and already had failed previous non-surgical weight loss attempts.

Patients who underwent previous bariatric surgery, patients with secondary obesity due to endocrine or metabolic diseases, patients with psychiatric disorders, patients with endoscopic findings of sever esophagitis or gastritis, or ulcers at the lesser curvature of the stomach, and patients unfit for surgery were excluded.

\subsection{Preoperative Assessment}

Patients were interviewed and full history of their condition was taken. Thorough clinical examination was done to exclude patients with secondary obesity. The patients' weight in kilograms and height in centimeters were recorded and BMI was calculated for each patients.

Routine laboratory investigations including complete blood count, liver and kidney function tests and coagulation profile were ordered. Chest X-ray, abdominal ultrasonography, and ECG were done to every patient. Pulmonary function tests were performed in patients with history of restrictive or obstructive respiratory disorders.

All patients were assessed for the presence of GERD with EGD and the diagnosis of GERD was based on the endoscopic features that ranged from varying degrees of esophagitis, patulous cardia with visible reflux to Barret's esophagus [12].

\subsection{Functional Assessment of the EGJ}

Functional assessment of the EGJ was done using esophageal manometry and ambulatory 24-hour esophageal $\mathrm{pH}$ monitoring which were carried out at Gastroenterology center (GEC) of Mansoura University.

Esophageal manometry was done while patients were fasting after stopping oral medications that may interfer with the study such as nitrate, anti-cholinergics, calcium channel blockers, proton pump inhibitors (PPIs), and prokinetics seven days before the test. Patients were submitted to a manometric evaluation of the characteristics of the LES by a water perfused eight lumen pressure catheter with an outside diameter of $4.5 \mathrm{~mm}$, side holes were $1 \mathrm{~cm}$ a part from each other and they are radially oriented by $360^{\circ}$ and were constantly perfused with distilled water from a perfusion pump at a rate of $0.5 \mathrm{ml} / \mathrm{min}$. Each channel was connected to pressure transducers which transmits data into a personal computer via (PC Polygraph ID Motility System, MedtronicSynectics, Sweden). A station pull-through technique was used and the probe was withdrawn $0.5 \mathrm{~cm}$ each time and kept at each level for at least 30 seconds or until the recording became stable.

The LES resting pressure, total and abdominal length were measured. The normal LES pressure ranged between 12.1 and $25 \mathrm{mmHg}$. The normal values for total and abdominal LES length were more than $4 \mathrm{~cm}$ and more than $1 \mathrm{~cm}$, 
respectively. The presence of incompetent sphincter was defined if one of the following parameters was present: LES resting pressure less or equal to $6 \mathrm{mmHg}$, total length less than $20 \mathrm{~mm}$, or abdominal length less than $10 \mathrm{~mm}$ [13].

Ambulatory 24-hour esophageal $\mathrm{pH}$ monitoring was performed in the fasting state after stopping antacids, prokinetics, and PPIs seven days prior to the test as in esophageal manometry. A disposable antimony or glass in gold $\mathrm{pH}$ electrodes was passed and secured to the nose with an electrode placed $5 \mathrm{~cm}$ above the manometrically determined LES and the electrode was connected to a portable, Digtrapper MKIII (Synectics medical Sweden). The patients were ambulatory throughout all recordings and were instructed to follow their usual pattern of living. Reflux symptoms, meals, and resting periods were recorded in a diary by the patients. The $\mathrm{pH}$ data and information given in the diary were evaluated by computer software.

The data were incorporated into a composite score called the DeMeester score [14]. This score takes into account six elements: (a) number of reflux episodes; (b) number of reflux episodes longer than $5 \mathrm{~min}$; (c) duration of the longest reflux episode; (d) percentage of time the $\mathrm{pH}$ is less than 4 for the total duration of the study; and (e) in the upright and (f) supine position. A score greater than 14.7 defined pathological acid reflux.

\subsection{Operative Procedure}

Written informed consents were obtained from all patients regarding the nature and possible complications of the procedure. Patients were given a prophylactic dose of low molecular weight heparin subcutaneously on the evening of admission and daily thereafter during the hospital stay and sequential compression stockings were used.

An epidural catheter was placed intraoperatively for postoperative pain management. Two grams of cefazolin were parentrally administered to all patients approximately 30 minutes before the incision and another gram was administered within 12 hours of the operation. LSG were performed by the conventional technique as described by Frezza et al. [15].

\subsection{Postoperative Care}

Opioid-sparing multimodal analgesic strategies, including local anesthetic wound infiltration and nonsteroidal antiinflammatory medications were used for postoperative pain control, unless contraindicated as in patients with obstructive sleep apnea (OSA) to avoid the risk of respiratory depression.

On the second or third postoperative day an upper GI contrast study was used to determine if there were any leaks from the gastric tube. The nasogastric tube was removed once gastric leak was excluded and the patient began a clear liquid diet as tolerated. The abdominal drain was removed on the second or third postoperative day and the patient was discharged afterwards. Abdominal stitches were removed ten days after surgery.

On discharge, patients were advised to wear elastic compression stockings for two weeks postoperatively and use esomeprazole $40 \mathrm{mg}$ once per day for six weeks. Instructions about the postoperative dietary regimen were given to the patients on discharge.

\subsection{Follow-up}

Patients were instructed to visit the outpatient clinic every week in the first month, every two weeks in the second and third months, and at 6, 9, 12, and 24 months after surgery. During the first visit, general and abdominal examinations were done and more solid diet was introduced as tolerated by the patient. At every three months, weight determination, fasting and post prandial glucose levels for diabetic patients, triglycerides and total cholesterol levels were assessed. EGD, esophageal manometry, and 24-hour $\mathrm{pH}$ monitoring were performed at six months after the procedure. The relevant data were collected and registred by the principal investigator.

\subsection{Statistical Analysis}

Data were extracted into fields of Excel spreadsheet and were analyzed using SPSS (Statistical Package for Social Sciences) version 21 under Microsoft Windows (Bristol, UK). Qualitative data were presented as numbers and percentages and were analyzed by Fisher's exact test or ChiSquare test when conveninet. Quantiative data were presented as mean \pm SD when there were normally distributed otherwise in the form of median and normal range. Paired student t-test was used for analysis of quantatitive data. $\mathrm{P}<0.05$ was considered to be statistically significant.

\section{Results}

\subsection{Patients' Characteristics}

Twenty patients with morbid obesity underwent functional assessement of EGJ before and six months after LSG. Patients were $16(80 \%)$ females and four $(20 \%)$ males of a mean age of $29.4 \pm 5.1$ (range, 19-38) years. The mean BMI of the patients at the time of surgery was $51.6 \pm 8.7$ (range, $39.1-71.8) \mathrm{kg} / \mathrm{m}^{2}$. Three (15\%) patients had BMI $>59.9$, nine (45\%) had BMI between 50 and 59.9 while eight (40\%) had BMI between 35 and 49.9. Patients' characterstics and demographic data are illustrated in table 1.

Table 1. Demographic data, preoperative esophageal manometry, and 24hour $\mathrm{pH}$-metry parameters of the study group.

\begin{tabular}{ll}
\hline Characteristic & Patients with morbid obesity \\
\hline Age in years (mean $\pm \mathrm{SD})$ & $29.4 \pm 5.1$ \\
Sex & \\
Male & $4(20 \%)$ \\
Female & $16(80 \%)$ \\
BMI $\left(\mathrm{kg} / \mathrm{m}^{2}\right)($ mean $\pm \mathrm{SD})$ & $51.6 \pm 8.7$ \\
Weight $(\mathrm{kg})($ mean $\pm \mathrm{SD})$ & $135.9 \pm 25.4$ \\
Height $\left(\mathrm{m}^{2}\right)($ mean $\pm \mathrm{SD})$ & $163.2 \pm 7.6$ \\
BMI group & \\
\hline
\end{tabular}




\begin{tabular}{ll}
\hline Characteristic & Patients with morbid obesity \\
\hline Group I (BMI $35-49.9)$ & $8(40 \%)$ \\
Group II (BMI 50 - 59.9) & $9(45 \%)$ \\
Group III (BMI > 59.9) & $3(15 \%)$ \\
Symptoms & \\
Symptomatic GERD & $7(35 \%)$ \\
Asymptomatic GERD & $13(65 \%)$ \\
Endoscopy & \\
Reflux esophagitis & $7(35 \%)$ \\
Mild gastritis & $3(15 \%)$ \\
Mild Duodenitis & $2(10 \%)$ \\
Combined gastritis and Duodenitis & $8(40 \%)$ \\
Hiatus hernia & 0 \\
Normal & 7 \\
24 hour pH-metry (DeMeester score) & \\
Abnormal acid score & $7(35 \%)$ \\
Normal acid score & $13(65 \%)$ \\
Esophageal manometry & \\
Hypotensive LES & 0 \\
Normal LES pressure & $20(100 \%)$ \\
Short total LES length & 0 \\
Short abdominal LES length & 0 \\
\hline
\end{tabular}

Six $(30 \%)$ patients had type 2 diabetes mellietus (T2DM) and were on subcutaneous insulin for glucose control, eleven $(55 \%)$ patients was hypertensive on antihypertension medications, nine (45\%) patients were dyslipidemic on statins, five (25\%) patients had OSA, eleven (55\%) patients had chronic joint pain and two $(10 \%)$ patients were found to have incidental gallbladder stones.

\subsection{Weight Loss and Improvement of Co-morbidities}

At three months after LSG, a statistically significant ( $\mathrm{p}=$ $0.0018)$ decrease in BMI $\left(43.4 \pm 6.8 \mathrm{~kg} / \mathrm{m}^{2}\right)$ was observed in comparison with the preoperative value. Follow-up for 24 months confirmed further statistically significant $(\mathrm{p}<$ $0.0001)$ decrease in BMI $\left(28.7 \pm 3.5 \mathrm{~kg} / \mathrm{m}^{2}\right)$. At 24 months of follow-up, the excess weight loss percentage (EWL\%) was $83.9 \pm 7.6$ and the excess body mass index loss percentage
(EBMIL\%) was $87.8 \pm 8.8$.

Regarding the improvement of obesity-related comorbidities, $100 \%$ of patients with T2DM, $81.8 \%$ of hypertensive patients, $77.7 \%$ of patients with dyslipidemia, $80 \%$ of patients with OSA and $72.7 \%$ of patients with chronic joint pain showed significant improvement or resoultion of their associated conditions.

\subsection{Clinical Evaluation by Reporting of GERD Symptoms}

Thirteen (65\%) patients had no symptoms related to GERD preoperatively, all of these patients remained symptom-free after LSG. Seven (35\%) patients had preoperative symptoms of GERD, three reported no change in their symptoms at six months of follow-up, and four reported significant improvement of their symptoms six months after LSG.

\subsection{Endoscopic Evaluation}

Preoperative EGD revealed no evidence of GERD in 13 $(65 \%)$ patients and evident GERD in seven $(35 \%)$ patients, four of them had no reflux in the postoperative endoscopy and three remained the same in exact accord with the clinical symptoms reporting of these patients.

\subsection{Evaluation by Esophageal Manometry}

Overall, no significant changes in the manometric parameters (LES pressure, total and abdominal length) were noticed in the patients studied (table 2). However, a significant decrease in the resting LES pressure after LSG was noticed in patients with no preoperative symptoms of GERD (table 3). No significant decrease in the resting LES pressure was observed in patients with symptomatic GERD after LSG (tables $4 \& 5$ ). No significant changes in total and abdominal esophageal length were observed in either patients with no preoperative symptoms, or patients with symptomatic GERD.

Table 2. Changes in manometric parameters overall (20 patients).

\begin{tabular}{|c|c|c|c|}
\hline Variable & Preoperative & Postoperative & P value \\
\hline LES resting pressure $(\mathrm{mmHg})$ & $34.2 \pm 9.5$ & $28.4 \pm 9$ & 0.054 \\
\hline Total LES length $(\mathrm{cm})$ & $4 \pm 0.7$ & $4.2 \pm 0.9$ & 0.43 \\
\hline Abdominal LES length $(\mathrm{cm})$ & $2.8 \pm 0.6$ & $3.2 \pm 0.8$ & 0.08 \\
\hline
\end{tabular}

Table 3. Changes in manometric parameters in patients with no preoperative symptoms (13 patients).

\begin{tabular}{|c|c|c|c|}
\hline Variable & Preoperative & Postoperative & P value \\
\hline LES resting pressure $(\mathrm{mmHg})$ & $35.4 \pm 8.1$ & $28.5 \pm 4.6$ & 0.01 \\
\hline Total LES length $(\mathrm{cm})$ & $4.1 \pm 0.7$ & $4.1 \pm 0.7$ & 1 \\
\hline Abdominal LES length $(\mathrm{cm})$ & $2.8 \pm 0.6$ & $3.2 \pm 0.7$ & 0.102 \\
\hline
\end{tabular}

Table 4. Changes in manometric parameters in patients with unresolved GERD (Three patients).

\begin{tabular}{|c|c|c|c|}
\hline Variable & Preoperative & Postoperative & P value \\
\hline LES resting pressure $(\mathrm{mmHg})$ & $26.5 \pm 12.3$ & $26.2 \pm 16.6$ & 0.98 \\
\hline Total LES length $(\mathrm{cm})$ & $4 \pm 0.8$ & $3.8 \pm 1$ & 0.8 \\
\hline Abdominal LES length $(\mathrm{cm})$ & $3 \pm 0.8$ & $2.8 \pm 1$ & 0.8 \\
\hline
\end{tabular}


Table 5. Changes in manometric parameters in patients with resolved GERD (Four patients).

\begin{tabular}{llll}
\hline Variable & Preoperative & Postoperative & P value \\
\hline LES resting pressure $(\mathrm{mmHg})$ & $36.2 \pm 11.8$ & $29.6 \pm 15.5$ & 0.52 \\
Total LES length $(\mathrm{cm})$ & $3.6 \pm 0.75$ & $4.7 \pm 1.4$ & 0.21 \\
Abdominal LES length $(\mathrm{cm})$ & $2.7 \pm 0.8$ & $3.5 \pm 1.2$ & 0.31 \\
\hline
\end{tabular}

\subsection{Evaluation by 24-Hour pH Monitoring}

Thirteen $(65 \%)$ patients had normal preoperative DeMeester score and normal total acid reflux time percentage. After LSG, all of them stayed normal except two patients who had elevated scores and prolonged total acid reflux time percentage.

On the other hand, seven (35\%) patients had high preoperative scores and prolonged total acid reflux time percentage, all of them got normalized postoperatively except two patients, one had his score further increased and the other showed slight improvement of LSG. The median DeMeester score and the median total acid reflux time \% showed a remarkable increase in patients with symptomatic GERD postoperatively (table 6).

Table 6. Changes in the parameters of pH-metry before and after sleeve in symptomatic patients.

\begin{tabular}{lll}
\hline Variable & Preoperative & Postoperative \\
\hline Median DeMeester score (range) & $30.1(19.6-87.5)$ & $51.6(23.4-77.1)$ \\
Median total acid reflux time \% (range) & $6.2(2.8-16.9)$ & $11(5.3-23.1)$ \\
\hline
\end{tabular}

\subsection{Concordance of the Clinical, Endoscopic, and Functional Parameters}

The concordance of the results of the studied parameters was classifed into three categories (figure 1): Absolute concordance if all the four parameters were aligned together, intermediate concordance if three of the four parameters were aligned, low concordance if only two of the parameters were aligned.

The category of absolute concordance included seven (35\%) patients who showed perfect alignment of all the investigated parameters, four of them were free of GERD pre- and postoperatively, one had GERD in all the parameters pre- and postoperatively, and two patients had signs of GERD and showed resolution after LSG in all parameters.

The category of intermediate concordance included 12 $(60 \%)$ patients. Five patients had concordant clinical, endoscopic and $\mathrm{pH}$-monitoring findings, yet the manometric results were conflicting, whereas seven patients had concordant clinical, endoscopic and manometric findings, yet the results of $\mathrm{pH}$-monitoring did not concur with the other parameters.

The category of low concordance included one (5\%) patient who had GERD based on clinical and manometric findings, however, the upper GI endoscopy and $\mathrm{pH}$ monitoring did not reveal signs of GERD.

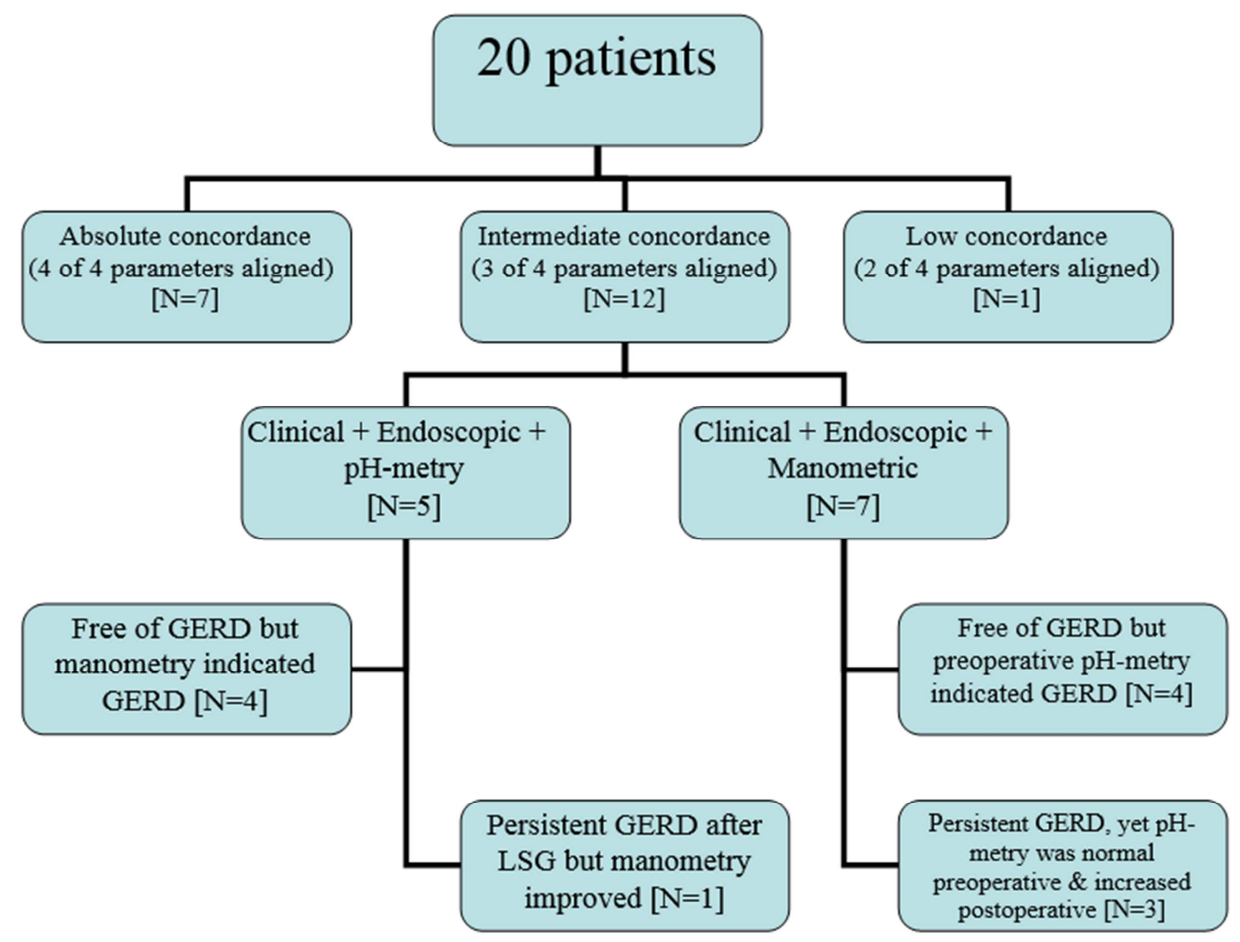

Figure 1. The conocordance of the investigated parameters in the studied group. 


\subsection{Technical Details}

The mean operation time was $115.5 \pm 47.4$ (Range, 45180) minutes, two (10\%) concomitant laparoscopic cholecystectomies were done for associated gallbladder stones. The mean postoperative hospital stay was $5 \pm 0.8$ (Range, 4-6) days, There was no conversion to open procedure.

\subsection{Complications}

The overall complication rate was $40 \%$, one $(5 \%)$ patient had subcutaneous port-site infection and was treated conservatively, four $(20 \%)$ patients developed symptomatic gallstones in the first postoperative year and were managed with laparoscopic cholecystectomy and one $(5 \%)$ patient was found to have port-site hernia at the site of the epigastric port and was managed with on-lay mesh repair at twelve months postoperatively. Two (10\%) patients developed symptoms of hair falling and dry skin at twelve months and were found to have Zinc deficiency that was adequately managed with oral Zinc supplementation.

\section{Discussion}

The effect of bariatric procedures on the incidence of GERD seems to be controversial with lots of unresolved issues. While certain procedures as laparoscopic Roux-en-Y gastric bypass (LRYGB) have been shown to improve symptoms related to GERD [9]; the effect of other procedures as LSG on GERD remains debatable, yet it appears that the esophageal function is affected by LSG, particularly the function of LES [16].

LRYGB has conferred consistent alleviation of GERD symptoms in patients with morbid obesity as shown by several studies. Frezza and coworkers [17] reported significant resolution of GERD symptoms in 152 patients who underwent LRYGB at 12 months of follow-up. Perry et al. [18] also published a series of 57 morbidly obese patients with significant improvement of GERD symptoms after LRYGB as reported by all patients at 18 months of follow-up.

As debated in the literature, reflux after LSG can deteriorate, alleviate, resolve after an initial increment, or even new-onset GERD can develop. These variable outcomes of GERD after LSG can be explained that the effect of LSG on the LES, and consequently on GERD, is not clearly understood yet. Although post-LSG GERD varies from 6.5 to $47.5 \%$ [19]; there is still no consensus on the incidence and severity of post-LSG GERD as concluded by a recent systematic review [20].

The factors contributing to post-LSG GERD include hypotension of the LES [21], blunting of the angle of His [22], decreased gastric compliance and volume leading to increased intragastric pressure [23], decreased gastric emptying [24], decreased plasma ghrelin with subsequent dysmotility [25], gastric sleeve shape [26], increase incidence of hiatal hernia [27], and the formation of a neo-fundus [28].
A recent study proposed alterations to the operative technique; the authors noticed a reduction in GERD by avoiding narrowing the EGJ, resecting more of the fundus, and repairing hiatal hernias. However, the development of GERD after SG is most probably multifactorial, hence the suggestions on preventive measures are usually unsatisfactory [29].

On the other hand, the postoperative improvement of GERD can be attributed to accelerated gastric emptying [24, 30], decreased abdominal obesity [4], increased long-term gastric compliance [31], restoration of the angle of His [22], decreased acid production [32], gastric sleeve shape [26], and decreased wall tension [33].

The present study included 20 patients who were mostly female in accord with the published literature [34, 35]. This sex differentiation is explained by the higher incidence of morbid obesity among females, and being more keen on their body-image and cosemtic aspects than male patients.

The data in the literature on manometric changes of the LES are controversial. There were no significant changes in the manometric parameters in the 20 patients studied in agreement with the results of Kleidi and associates [36] who found no significant alteration in the LES pressure.

However, a significant decrease in the resting LES pressure after LSG was noticed in patients with no pre- or postoperative symptoms of GERD concordant with Braghetto et al. [21] and Hayat et al. [37] who found a significant decrease in the postoperative LES pressure at six months after LSG. The authors [21] attributed this decrease to the partial division of the sling fibers of the cardia. Paradoxically, no significant changes in the resting LES pressure after LSG was found in patients with symptomatic GERD.

None of our patients showed an increase in the LES pressure postoperatively, on the other hand, Petersen \& Schneider [38] reported an increase in the LES pressure early and later after LSG as compared with the preoperative values. Burgerhart and colleagues [39] also disclosed a remarkable increase in the resting LES pressure after LSG.

Similarly, no significant changes in the total and abdominal LES length were observed in our patients hand in hand with the findings of Del Genio et al. [40] \& Kleidi et al [36]. Conversely, Braghetto and associates [21] disclosed that $70 \%$ of patients who underwent LSG had remarkable changes in the total and abdominal LES length postoperatively and Petersen et al. [41] reported a significant increase in total and abdominal LES length after LSG. These variable findings confirm what Curcic et al. [42] concluded that LES dysfunction may not accurately predict GERD symptoms.

As regards 24-hour $\mathrm{pH}$ monitoring of LES, 13 of our patients had normal preoperative DeMeester score and total acid reflux time percentage and most of them remained normal after LSG in agreement with Rebecchi and colleagues [43] who also demonstrated no changes in 24-hour $\mathrm{pH}$ monitoring after LSG among asymptomatic patients.

Only two patients with normal preoperative $\mathrm{pH}$-metry in our trial developed an increase in their postoperative scores similar to what other investigators $[36,37]$ have reported 
about the increase of acid reflux demonstrated by $\mathrm{pH}$ monitoring. Seven patients had high preoperative scores and all improved postoperatively which copes with the findings of another trial [43]. One patient had further increase in his score and another patient showed improvement of his score yet without reaching the normal levels.

The rationale for performing an upper GI endoscopy before bariatric surgery is to detect lesions that might potentially affect the type of surgery performed, cause complications in the immediate postoperative period, or result in symptoms after surgery. The role of upper GI endoscopy in the preoperative assessment of patients undergoing LSG is often based on the presence or absence of clinical symptoms. The performance of an upper GI endoscopy in patients with reflux symptoms and/or dyspepsia has been recommended by recent guideline [44, 45].

On the other hand, the value of a routine endoscopy before LSG in the asymptomatic patients remains controversial, although an upper GI endoscopy in asymptomatic patients can identify lesions that may alter surgical management; there are no studies that evaluated the effect of a preoperative endoscopy on the surgical outcome. Despite what has been mentioned, the European guidelines still recommend performing preoperative upper GI endoscopy in all patients including the asymptomatic ones before bariatric surgery [46].

Following the guidelines aforementioned, upper GI endoscopy was performed in all of our patients including 13 asymptomatic patients who had normal endoscopic examination. Evident preoperative GERD was detected in seven patients, four of them had normal postoperative endoscopic examination and three had persistent evidence of reflux.

According to the four parameters investigated (clinical, endoscopic, manometric and $\mathrm{pH}$-metry), the concordance of the results of these parameters was classified into three categories: absolute concordance if all the four parameters were aligned together, intermediate concordance if three of the four parameters were aligned, and low concordance if only two of the parameters were aligned.

Perfect matching of all the parameters was noticed in only $35 \%$ of the patients studied, whereas moderate concordance was observed in $60 \%$. This implies that only one-third of patients had a sure diagnosis or exclusion of GERD based on all of the investigatory tools which assert the problem of the absence of a gold-standard for the accurate diagnosis of GERD. As a recent meta-analysis implied, the objective esophageal function tests had paradoxical outcomes which rendered the exact effect of LSG on the prevelance of GERD unknown [47].

The present study is limited by the small cohort of patients included and lack of using an objective scoring system for evaluation of clinical symptoms reported by the patients.

\section{Conclusions}

The impact of LSG on patients with morbid obesity in our study seems to be more consistent than that reported in the literature, since patients either showed improvement or persistence of preoperative GERD symptoms but none of the patients developed new-onset GERD or deterioration of an already existing GERD.

Esophageal manometry has a limited utility in the detection or exclusion of GERD postoperatively since the significant decrease in the resting LES pressure observed was not associated with symptoms of GERD. On the other hand, 24-hour $\mathrm{pH}$ monitoring was able to detect improvement or persistence of GERD in the patients studied.

Only one-third of the patients demonestrated perfect allignment of the four parameters studied confirming the presence or absence of clinical GERD. This emphasized the difficult diagnosis of GERD in general and the need to define a gold-standard for the diagnosis based not only on clinical symptoms; but also on other objective scales.

\section{References}

[1] Hampel H, Abraham NS, El-Serag HB (2005) Meta-analysis: obesity and the risk for gastroesophageal reflux disease and its complications. Ann Intern Med, 143: 199-211.

[2] Mittal R, Holloway R, Penagini R, Blackshaw L, Dent J (1995): Transient lower esophageal sphincter relaxation. Gastroenterology, vol. 109, no. 2, pp. 601-610.

[3] Dent J, Dodds W, Hogan W, Toouli J (1988): Factors that influence induction of gastroesophageal reflux in normal human subjects. Digestive Diseases and Sciences, vol. 33, no. 3, pp. 270-275.

[4] Pandolfino JE, Kim H, Ghosh SK, Clarke JO, Zhang Q, Kahrilas P (2007): High-resolution manometry of the EGJ: an analysis of crural diaphragm function in GERD. American Journal of Gastroenterology, vol. 102, no. 5, pp. 1056-1063.

[5] Ayazi S, Hagen JA, Chan LS, et al. (2009): Obesity and gastroesophageal reflux: quantifying the association between body mass index, esophageal acid exposure, and lower esophageal sphincter status in a large series of patients with reflux symptoms. Journal of Gastrointestinal Surgery, vol. 13, no. 8, pp. 1440-1447.

[6] Wu JC, Mui L, Cheung CM, Chan Y, Sung JJ (2007): Obesity Is Associated With Increased Transient Lower Esophageal Sphincter Relaxation. Gastroenterology, vol. 132, no. 3, pp. 883-889.

[7] Küper MA, Kramer KM, Kirschniak A, Zdichavsky M, Schneider JH, Stüker D, Kratt T, Königsrainer A, Granderath FA (2009): Dysfunction of the lower esophageal sphincter and dysmotility of the tubular esophagus in morbidly obese patients. Obes Surg, 19: 1143-1149.

[8] Barham CP, Gotley DC, Mills A, Alderson D (1995): Precipitating causes of acid reflux episodes in ambulant patients with gastroesophageal reflux disease. Gut, vol. 36, no. 4, pp. 505-510.

[9] Tai C, Lee Y, Wu M, et al. (2009): The effect of roux-en-Y gastric bypass on gastroesophageal reflux disease in morbidly obese Chinese patients. Obesity Surgery, vol. 19, no. 5, pp. 565-570. 
[10] Katz PO, Gerson LB, Vela MF (2013): Guidelines for the diagnosis and management of gastroesophageal reflux disease. American Journal of Gastroenterology, vol. 108, pp. 308-328.

[11] Avidan B, Sonnenberg A, Schnell TG, Sontag SJ (2002): There are no reliable symptoms for erosive esophagitis and Barrett's oesophagus: endoscopic diagnosis is still essential. Alimentary Pharmacology and Therapeutics, vol. 16, no. 4, pp. 735-742.

[12] Tefera L, Fein M, Ritter MP, Bremner CG, Crookes PF, Peters $\mathrm{JH}$, et al. (1997): Can the combination of symptoms and endoscopy confirm the presence of gastroesophageal reflux disease? Am Surg, 63: 933-6.

[13] Kahrilas PJ, Clause RE, Hogan WG (1994): American Gastroenterology Association technical review on the clinical use of esophageal manometry. Gastroenterology, 107: 18651884 .

[14] DeMeester TR, Johnson LF: Development of the 24 hours intraesophageal $\mathrm{pH}$ monitoring composite scoring system. In: DeMeester TR, Skinner DB, Eds. Esophageal disorders: Pathophysiology and therapy. New York, NY: Raven Press, 1985: 561-570.

[15] Frezza EE, Reddy S, Gee LL, et al. (2009): Complications After Sleeve Gastrectomy for Morbid Obesity. Obes Surg, 19: 684-687.

[16] Tolone S, Savarino E, Yates RB. (2016): The impact of bariatric surgery on esophageal function. Ann N Y Acad Sci. doi: 10.1111/nyas.13107. [Epub ahead of print].

[17] Frezza EE, Ikramuddin S, Gourash W, et al. (2002): Symptomatic improvement in gastroesophageal reflux disease (GERD) following laparoscopic Roux-en-Y gastric bypass. Surg Endosc, 16: 1027-31.

[18] Perry Y, Courcoulas AP, Fernando HC, et al. (2004): Laparoscopic Roux-en-Y gastric bypass for recalcitrant gastroesophageal reflux disease in morbidly obese patients. JSLS, 8: 19-23.

[19] Carter PR, LeBlanc KA, Hausmann MG, Kleinpeter KP, deBarros SN, Jones SM (2011): Association between gastroesophageal reflux disease and laparoscopic sleeve gastrectomy. Surg Obes Relat Dis, 7: 569-572.

[20] Chiu S, Birch DW, Shi X, Sharma AM, Karmali S (2011): Effect of sleeve gastrectomy on gastroesophageal reflux disease: a systematic review. Surg Obes Relat Dis, 7: 510-515.

[21] Braghetto I, Lanzarini E, Korn O, Valladares H, Molina JC, Henriquez A (2010): Manometric changes of the lower esophageal sphincter after sleeve gastrectomy in obese patients. Obesity Surgery, vol. 20, no. 3, pp. 357-362.

[22] Himpens J, Dapri G, Cadiere GB (2006): A prospective randomized study between laparoscopic gastric banding and laparoscopic isolated sleeve gastrectomy: results after 1 and 3 years. Obesity Surgery, vol. 16, no. 11, pp. 1450-1456.

[23] R. T. Yehoshua, L. A. Eidelman, M. Stein et al. (2008): "Laparoscopic Sleeve gastrectomy-volume and pressure assessment", Obesity Surgery, vol. 18, no. 9, pp. 1083-1088.

[24] J. Melissas, A. Leventi, I. Klinaki et al. (2012): "Alterations of global gastrointestinal motility after sleeve gastrectomy", Annals of Surgery, vol. 258, no. 6, pp. 976-982.
[25] M. Nahata, S. Muto, N. Oridate et al. (2012): "Impaired ghrelin signaling is associated with gastrointestinal dysmotility in rats with gastroesophageal reflux disease", American Journal of Physiology-Gastrointestinal and Liver Physiology, vol. 303, no. 1, pp. G42-G53.

[26] O. Lazoura, D. Zacharoulis, G. Triantafyllidis et al. (2011): "Symptoms of gastroesophageal reflux following laparoscopic sleeve gastrectomy are related to the final shape of the sleeve as depicted by radiology", Obesity Surgery, vol. 21, no. 3, pp. 295-299.

[27] T. Baumann, J. Grueneberger, G. Pache et al. (2011): “Threedimensional stomach analysis with computed tomography after laparoscopic sleeve gastrectomy: sleeve dilation and thoracic migration", Surgical Endoscopy and Other Interventional Techniques, vol. 25, no. 7, pp. 2323-2329.

[28] J. Himpens, J. Dobbeleir, and G. Peeters (2010): "Long-term results of laparoscopic sleeve gastrectomy for obesity", Annals of Surgery, vol. 252, no. 2, pp. 319-324.

[29] Daes J, Jimenez ME, Said N, Daza JC, Dennis R (2012): Laparoscopic sleeve gastrectomy: symptoms of gastroesophageal reflux can be reduced by changes in surgical technique. Obes Surg, 22: 1874-1879.

[30] S. Shah, P. Shah, J. Todkar, M. Gagner, S. Sonar, and S. Solav (2010): "Prospective controlled study of effect of laparoscopic sleeve gastrectomy on small bowel transit time and gastric emptying half-time in morbidly obese patients with type 2 diabetes mellitus", Surgery for Obesity and Related Diseases, vol. 6 , no. 2, pp. 152-157.

[31] S. N. Karamanakos, K. Vagenas, F. Kalfarentzos, and T. K. Alexandrides (2008): "Weight loss, appetite suppression, and changes in fasting and postprandial ghrelin and peptide-YY levels after Roux-en-Y gastric bypass and sleeve gastrectomy: a prospective, double blind study", Annals of surgery, vol. 247, no. 3, pp. 401-407.

[32] X. Yao and J. G. Forte (2003): "Cell Biology of Acid Secretion by the Parietal Cell", Annual Review of Physiology, vol. 65 , pp. 103-131.

[33] S. Santoro (2007): "Technical aspects in sleeve gastrectomy", Obesity Surgery, vol. 17, no. 11, pp. 1534-1535.

[34] Elbanna H, Ghnnam W, Negm A, et al. Impact of Preoperative Body Mass Index (BMI) on The Final Outcome After Laparoscopic Sleeve Gastrectomy for Morbid Obesity. Turkish journal of surgery, 2016; [Epub ahead of print].

[35] Abdallah E, Emile SH, Elfeki H. Laparoscopic Sleeve Gastrectomy With or Without Staple Line Inversion and Distal Fixation to the Transverse Mesocolon: Impact on Early Postoperative Outcomes. Obes Surg, 2016 Jul 5; [Epub ahead of print].

[36] Kleidi E, Theodorou D, Albanopoulos K, Menenakos E, Karvelis MA, et al. (2013): The effect of laparoscopic sleeve gastrectomy on the antireflux mechanism: can it be minimized? Surg Endosc, 27: 4625-4630.

[37] Hayat JO, Manson S, Wan A, Poulis AP, Yazaki E et al. (2014): Effects of sleeve gastrectomy on gastroesophageal reflux and esophagogastric motility? Expert Rev Gastroenterol Hepatol, 8: 445-52.

[38] Petersen WV, Schneider JH (2012): Functional importance of laparoscopic sleeve gastrectomy for the lower esophageal sphincter in patients with morbid obesity. Obes Surg, 22: 949. 
[39] Burgerhart JS, Schotborgh CA, Schoon EJ, Smulders JF, van de Meeberg PC, et al. (2014): Effect of sleeve gastrectomy on gastroesophageal reflux. Obes Surg, 24: 1436-1441.

[40] Del Genio G, Tolone S, Limongelli P, Brusciano L, D'Alessandro A, et al. (2014): Sleeve gastrectomy and development of "de novo" gastroesophageal reflux. Obes Surg, 24: 71-77.

[41] Petersen WV, Meile T, Kuper MA, Zdichoesky KM, Korigsrainer A, Schneider JH (2012): Functional importance of laparoscopic sleeve gastrectomy for the lower esophageal sphincter in patients with morbid obesity. Obes Surg, 23: 360366.

[42] Curcic J, Roy S, Schwizer A, Kaufman E, Forras-Kaufman Z, Menne D, Hebbard GS, Treier R, Boesiger P, Steingoetter A, Fried M, Schwizer W, Pal A, Fox M (2014): Abnormal structure and function of the esophagogastric junction and proximal stomach in gastroesophageal reflux disease. $\mathrm{Am} \mathrm{J}$ Gastroenterol, 109 (5): 658-67.

[43] Rebecchi F, Allaix ME, Giaccone C, Ugliono E, Scozzari G, et al. (2014): Gastroesophageal reflux disease and laparoscopic sleeve gastrectomy: a physiopathologic evaluation. Ann Surg, 260: 909-914.

[44] Ikenberry SO, Harrison ME, Lichtenstein D, et al. (2007): American Society for Gastrointestinal Endoscopy. The role of endoscopy in dyspepsia. Gastrointest Endosc, 66: 1071-5.

[45] Lichtenstein DR, Cash BD, Davilla R, et al. (2007): American Society for Gastrointestinal Endoscopy. Role of endoscopy in the management of GERD. Gastrointest Endosc, 66: 219-24.

[46] Sauerland S, Angrisani L, Belachew M, et al. (2005): European Association for Endoscopic Surgery. Obesity surgery: evidence-based guidelines of the European Association for Endoscopic Surgery (EAES). Surg Endosc, 19: 200-21.

[47] Oor JE, Roks DJ, Unlu C, Hazebroek EJ. (2016): Laparoscopic sleeve gastrectomy and gastroesophageal reflux disease: a systematic review and meta-analysis. Am J Surg, 211 (1): 250-67. Doi: 10.1016/j.amjsurg.2015.05.031. 